NOTE

\title{
Characterization of Austrian koi herpesvirus samples based on the ORF40 region
}

\author{
A. Marek ${ }^{*}$, O. Schachner, I. Bilic, M. Hess \\ Clinic for Avian, Reptile and Fish Medicine, Department for Farm Animals and Veterinary Public Health, \\ University of Veterinary Medicine Vienna, Veterinärplatz 1, 1210 Vienna
}

\begin{abstract}
Using a PCR that amplifies a region of the thymidine kinase (TK) gene, an epidemic spread of koi herpesvirus (KHV) was determined in koi carps in Austria in 2007. A total of 15 virus samples from different locations in Austria were analyzed to determine their genetic relatedness following PCR and nucleic acid sequencing of the open reading frame 40 (ORF40) region of the KHV genome. ORF40-specific PCR amplification products that were obtained from tissue samples shared $100 \%$ nucleotide sequence identity with the published sequence of the Japanese strain of KHV. The ORF40 sequence of one isolate from the UK that was included in the present study was $100 \%$ identical with the published sequence of an Israeli strain of KHV. This is the first study that used a larger number of samples and a PCR method, which allowed distinguishing all 3 strains of KHV. The present investigation provides information on the epidemiology of KHV infections in Europe and describes a useful molecular tool for epidemiological studies.
\end{abstract}

KEY WORDS: Cyprinus carpio koi $\cdot$ Koi herpesvirus $\cdot$ Sequence analysis $\cdot$ ORF40

Resale or republication not permitted without written consent of the publisher

\section{INTRODUCTION}

Koi herpesvirus (KHV) is the etiological agent of a highly contagious cyprinid disease affecting populations of koi Cyprinus carpio koi as well as wild and farmed common carp C. carpio carpio L. Natural KHV infections have also been recorded from ghost carp $C$. carpio goi. The disease can cause high mortality and severe economic losses in both koi and common carp culture. After the first records from Israel and Germany in the late 1990s, KHV has been reported from many other countries in Europe, Asia, South Africa and the USA (Haenen et al. 2004). The rapid worldwide spread of the virus has been attributed to the intensive culture of carp and the largely unregulated commercial trade (Gilad et al. 2003). Therefore, KHV disease is listed as a notifiable disease under EU legislation and by the World Organisation for Animal Health (Office International des Epizooties OIE).

Most of the studies on KHV have so far been devoted to diagnosis and control of infection, and only a few studies have investigated the genetic differences be- tween KHV isolates from different geographical areas (Bigarre et al. 2009, Kurita et al. 2009). Moreover, the role of these genetic differences in effecting different levels of virulence in KHV strains is not known. The evolution and geographic distribution of KHV strains are also largely unknown.

Based on phylogenetic analysis of its genome sequence, KHV was classified in the family Alloherpesviridae, which encompasses herpesviruses of fish and amphibians (Davison et al. 2009). The genome of $\mathrm{KHV}$ is a linear double-stranded DNA of approximately $295 \mathrm{~kb}$. Comparisons of the genomes of $\mathrm{KHV}$ isolates from different geographical areas by restriction enzyme analysis (Gilad et al. 2002, Haenen et al. 2004) or nucleotide sequence analysis (Ishioka et al. 2005) have shown them to be identical. Moreover, the polypeptides of KHV isolates from different geographical regions were found to be similar (Gilad et al. 2002, 2003).

Recently, the genomes of 3 different isolates from Japan (J), the USA (U) and Israel (I) were completely sequenced and their analyses revealed the presence 
of 156 presumably protein-encoding open reading frames (ORFs). In each strain, several genes were fragmented by frameshifts which are likely to render the encoded proteins nonfunctional. Most of the affected genes encode predicted membrane glycoproteins and at least some of them occurred in vivo, suggesting a role of gene loss in the emergence of KHV disease (Aoki et al. 2007). The 3 available full-length genomes were aligned and inspected visually for differences among the strains. Since the published sequences of the $\mathrm{J}, \mathrm{U}$ and I isolates differ in ORF40, we decided to use this region to compare samples collected in 2007. Moreover, ORF40 encodes a predicted membrane glycoprotein and is broken at least twice in the same place in $\mathrm{J}, \mathrm{U}$ and $\mathrm{I}$, once more in $\mathrm{J}$, and frameshifted once more in U (Aoki et al. 2007). In general, membrane proteins are relevant both for virus-host cell interactions and for the host immune response, and complete sequence analysis revealed 27 predicted membrane proteins. However, none of them was identified and functionally characterized, and it is still not known which of them are major components of the virion envelope. Until now, only ORF81 was shown to encode one of the membrane proteins of KHV (Rosenkranz et al. 2008).

\section{MATERIALS AND METHODS}

In the present study, we investigated the nucleotide sequences of the ORF40 region of $15 \mathrm{KHV}$ samples from Austria and 1 isolate from the UK. In order to determine their genetic relatedness, we compared their ORF40 nucleotide sequences with those of completely sequenced KHV isolates from Japan, Israel and the USA.

Some characteristics of the samples and the infected fish used in the study are listed in Table 1. Most samples have been prepared from single fish mortalities. In cases where organs from more than one fish were pooled, all fish displayed similar clinical signs of disease or were all clinically healthy. In addition, we included one virus that was isolated in the UK (K. Way pers. comm.) in the analyses.

Organ pools consisting of spleen, head kidney, hepatopancreas, soft tissue of gills and brain from 1 to 3 individual fish were tested. Total DNA was isolated from $25 \mathrm{mg}$ of tissues using the DNeasy Blood and Tissue Kit (Qiagen) according to the manufacturer's in- structions. DNA was eluted with $100 \mu \mathrm{l}$ AE buffer (Qiagen).

Diagnosis of KHV was based on clinical signs and on detection of KHV DNA in tissues by thymidine kinase (TK) PCR (Bercovier et al. 2005). PCR was carried out using Illustra ${ }^{\circledR}$ puRe Taq Ready-To-Go PCR beads (GE Healthcare). Products were visualized using UV light following electrophoresis and ethidium bromide staining (data not shown).

Subsequent PCR for the ORF40 region was carried out using Illustra ${ }^{\circledR}$ puRe Taq Ready-To-Go PCR beads (GE Healthcare). Each reaction contained $0.8 \mu \mathrm{M}$ (final concentration) of each ORF40 forward (TTG AAA CGG TGA GGC AGC CAT) and ORF40 reverse (CAA CTG CAA CAT ACC GTC AAG) primer (Aoki et al. 2007 ) and $7 \mu \mathrm{l}$ of DNA in a final reaction volume of $25 \mu \mathrm{l}$. One cycle of $15 \mathrm{~min}$ at $95^{\circ} \mathrm{C}$ was followed by 5 amplification cycles of $30 \mathrm{~s}$ at $95^{\circ} \mathrm{C}, 30 \mathrm{~s}$ at $57^{\circ} \mathrm{C}$ and $1 \mathrm{~min}$ at $72^{\circ} \mathrm{C}$; 35 amplification cycles of $30 \mathrm{~s}$ at $95^{\circ} \mathrm{C}$, $30 \mathrm{~s}$ at $52^{\circ} \mathrm{C}$ and $1 \mathrm{~min}$ at $72^{\circ} \mathrm{C}$; and a final extension step for $10 \mathrm{~min}$ at $72^{\circ} \mathrm{C}$. The oligonucleotide primer pairs used in this study amplify a 458, 460 and $445 \mathrm{bp}$ region of the $\mathrm{U}, \mathrm{I}$ and $\mathrm{J}$ KHV genomes, respectively (GenBank DQ657948, DQ177346 and AP008984, respectively). The PCR products of the expected length were visualized (data not shown).

After gel electrophoresis, PCR products were extracted from the gel using the QIAquick Gel Extraction Kit (Qiagen) according to the manufacturer's recommendations. Where sufficient PCR product was amplified, eluted PCR products were directly sequenced in both directions using ORF40 forward and ORF40 reverse primers (Aoki et al. 2007). Sequencing

Table 1. Characteristics of koi herpesvirus (KHV) samples from Austria used in this study. Signs of disease - 1: unapparent; 2: loss of gill mucus; 3: increase in mucus on skin and gills; 4: loss of skin mucus; 5 : congestion mainly in fins; 6: enophthalmia; 7: gill necrosis; 8: splenomegalia; 9: intestinal katarrh without ingesta; nd: no data

\begin{tabular}{|lccccc|}
\hline $\begin{array}{l}\text { Sample } \\
\text { no. }\end{array}$ & $\begin{array}{c}\text { No. of } \\
\text { koi pool }^{-1}\end{array}$ & $\begin{array}{c}\text { Fish total } \\
\text { length (cm) }\end{array}$ & $\begin{array}{c}\text { Sampling date } \\
\text { (dd.mm.yy) }\end{array}$ & Location & $\begin{array}{c}\text { Signs of } \\
\text { disease }\end{array}$ \\
\hline $07-3674$ & 1 & nd & 10.05 .2007 & Lower Austria & nd \\
$07-4141$ & 2 & $11-12$ & 22.05 .2007 & Styria & 1 \\
$07-4395$ & 1 & 40 & 31.05 .2007 & Styria & $5,6,7,8,9$ \\
$07-4396$ & 3 & nd & 31.05 .2007 & Styria & nd \\
$07-4454$ & 2 & 22,29 & 04.06 .2007 & Lower Austria & $3,7,8$ \\
$07-4519$ & 1 & 36 & 04.06 .2007 & Lower Austria & $3,5,6,8,9$ \\
$07-4574$ & 1 & 18 & 06.06 .2007 & Tyrol & $4,6,8,9$ \\
$07-4608-1$ & 2 & 19,34 & 08.06 .2007 & Burgenland & $5,7,9$ \\
$07-4609$ & 1 & 25 & 11.06 .2007 & Vienna & $2,5,8,9$ \\
$07-5029$ & 1 & 20 & 19.06 .2007 & Upper Austria & 7 \\
$07-5032$ & 2 & nd & 19.06 .2007 & Carynthia & nd \\
$07-5033$ & 1 & 47 & 19.06 .2007 & Carynthia & $5,6,8$ \\
$07-5338$ & 1 & 42 & 27.06 .2007 & Carynthia & $2,4,6,7,8,9$ \\
$07-5875$ & 1 & 16 & 10.07 .2007 & Upper Austria & $4,6,7,8,9$ \\
$07-8123$ & 1 & 49 & 12.09 .2007 & Upper Austria & nd \\
\hline
\end{tabular}


services were provided by Eurofins MWG Operon. In other cases, eluted PCR products were cloned into pCR® 4-TOPO vector using the TOPO TA Cloning ${ }^{\circledR}$ Kit (Invitrogen) according to the manufacturer's protocol. Positive recombinant plasmids were sequenced by fluorescence-based sequencing using M13 primers. Each clone was sequenced in both directions.

Obtained nucleotide sequences for the ORF40 region of the Austrian and UK isolates were identified as KHV sequences using BLAST search (data not shown). For sequence analysis, primer binding sites were excluded and 416, 418 and $403 \mathrm{bp}$ fragments of the U, I and J KHV genomes, respectively, were analyzed. The sequences of the Austrian and UK isolates were compared to each other and to the ORF40 sequences of already published, completely sequenced KHV isolates from Japan, Israel and the USA. Assembly and analysis of sequences as well as the nucleotide alignments were performed using Accelrys Gene version 2.5 (Accelrys), Lasergene (DNASTAR) and BioEdit (Tom Hall, Ibis Biosciences) softwares.

\section{RESULTS AND DISCUSSION}

The analyzed portion of the ORF40 was $100 \%$ identical in all samples from Austria and was also 100\% identical to the Japanese isolate (GenBank AP008984) (Fig. 1). Therefore, the KHV that was detected in Austria in 2007 is related to the Japanese strain and presumably has been introduced from Asia. This result is in agreement with a very recent study identifying the Japanese strain (genotype) in most samples from the Netherlands (Bigarre et al. 2009). However, the presence of other strains (genotypes) in Austria cannot be discounted.

The nucleotide sequence of the ORF40 region of the isolate from the UK was $100 \%$ identical to the Israeli isolate (GenBank DQ177346) (Fig. 1). This KHV isolate from the UK presumably belongs to the Israeli strain. Interestingly, almost all samples from France were shown to belong to the U/I lineage (Bigarre et al. 2009).

In our study, nucleotide sequences could not be linked to clinical signs of the disease. Irrespective of

\section{$\begin{array}{lllllllll}10 & 20 & 30 & 40 & 50 & 60 & 70 & 80 & 90\end{array}$ \\ $\ldots|\ldots| \ldots|\ldots| \ldots|\ldots| \ldots|\ldots| \ldots|\ldots| \ldots|\ldots| \ldots|\ldots| \ldots|\ldots| \ldots|\ldots| \ldots|\ldots| \ldots|\ldots| \ldots|\ldots| \ldots \mid$ AP008984 J ATTGTACAGATGAACATTTGGTAACATTTGGTAACATTAGTAGTAGTACTCGAAGGCGCATTTCCTCGCGACGCTCGCTCTTTTGTTATCCAGGCTCCGT AUSTRIAN (15) ATTGTACAGATGAACATTTGGTAACATTTGGTAACATTAGTAGTAGTACTCGAAGGCGCATTTCCTCGCGACGCTCGCTCTTTTGTTATCCAGGCTCCGT DQ657948 U ATTGTACAGATGAACATTTGGTAACATT- - . - . - - -AGTAGTAGTACTCGAAGGCGCATTTCCTCGCGA--CTCGCTCTTTTGTTATCCAGGCTCCGT DQ177346 I ATTGTACAGATGAACATTTGGTAACATT--_-_-_-AGTAGTAGTACTCGAAGGCGCATTTCCTCGCGACGCTCGCTCTTTTGTTATCCAGGCTCCGT UK (1) ATTGTACAGATGAACATTTGGTAACATT-......-. AGTAGTAGTACTCGAAGGCGCATTTCCTCGCGACGCTCGCTCTTTTGTTATCCAGGCTCCGT \\ \begin{tabular}{rrrrrrrrr|r}
110 & 120 & 130 & 140 & 150 & 160 & 170 & 180 & 190 & 200
\end{tabular} $\ldots|\ldots| \ldots|\ldots| \ldots|\ldots| \ldots|\ldots| \ldots|\ldots| \ldots|\ldots| \ldots|\ldots| \ldots|\ldots| \ldots|\ldots| \ldots|\ldots| \ldots|\ldots| \ldots|\ldots| \ldots \mid$ AP008984 J CGTTGGCGTCTGCACAGCAGGACCCGGAGCACTATGAAGATCAGCAGACATCAAGAAGAGTCCCGAGCCGACTCCCAGCGCGATGATCACCCACGTCGGC AUSTRIAN (15) CGTTGGCGTCTGCACAGCAGGACCCCGAGCACTATGAAGATCAGCAGACATCAAGAAGAGTCCCGAGCCGACTCCCAGCGCGATGATCACCCACGTCGGC D0657948 U CGTTGGCGTCTGCACAGCAGGACCCCGAGCACTATGAAGATCAGCAGACATCAAGAAGAGTCCCGAGCCGACTCCCAGCGCGATGATCACCCACGTCGGC DQ177346 I CGTTGGCGTCTGCACAGCAGGACCCCGAGCACTATGAAGATCAGCAGACATCAAGAAGAGTCCCGAGCCGACTCCCAGCGCGATGATCACCCACGTCGGC UK (1) CGTTGGCGTCTGCACAGCAGGACCCCGAGCACTATGAAGATCAGCAGACATCAAGAAGAGTCCCGAGCCGACTCCCAGCGCGATGATCACCCACGTCGGC}

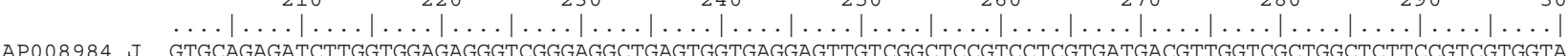
AUSTRIAN (15) GTGCAGAGATCTTGGTGGAGAGGGTCGGGAGGCTGAGTGGTGAGGAGTTGTCGGCTCCGTCCTCGTGATGACGTTGGTCGCTGGCTCTTCCGTCGTGGTA DQ657948 U GTGCAGAGATCTTGGTGGAGAGGTTGGGAGGCTGAGTGGTGAGGAGTTGTCGGCTCCGTCCTCGTGATGACGTTGGTCGCTGGCTCTTCCGTCGTGGTA DQ177346 I GTGCAGAGATCTTGGTGGAGAGGGTCGGGAGGCTGAGTGGTGAGGAGTTGTCGGCTCCGTCCTCGTGATGACGTTGGTCGCTGGCTCTTCCGTCGTGGTA UK (1) GTGCAGAGATCTTGGTGGAGAGGGTCGGGAGGCTGAGTGGTGAGGAGTTGTCGGCTCCGTCCTCGTGATGACGTTGGTCGCTGGCTCTTCCGTCGTGGTA

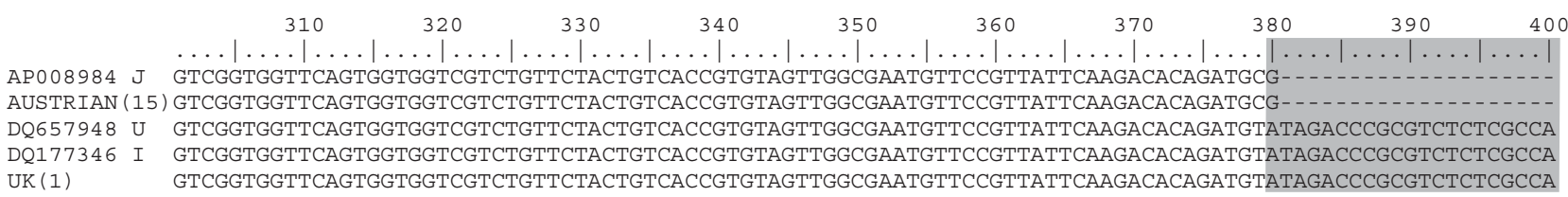

\begin{tabular}{|c|c|}
\hline & $\begin{array}{l}410 \\
. .1 \ldots\end{array}$ \\
\hline & СTTCTGATAGTCAGCGAACA \\
\hline J(15) & ---CTTCTGATAGTCAGCGAACAACT \\
\hline $48 \mathrm{U}$ & GAGCGCTTCTGATAGTCAGCGAACAACT \\
\hline $7346 I$ & GAGCGCTTCTGATAGTCAGCGAACAACT \\
\hline
\end{tabular}

Fig. 1. Comparison of the ORF40 nucleotide sequences of the Austrian and UK samples of koi herpesviruses (KHV) with the ORF40 sequences of completely sequenced KHV isolates from Japan (J), the USA (U) and Israel (I) (GenBank AP008984, DQ657948 and DQ177346, respectively). Number of samples having the sequence shown in brackets; shading shows differences 
the clinical appearance of individual hosts, all the KHV samples from Austria had 100\% identical nucleotide sequence of the ORF40 region (Table 1) and all belong to the Japanese strain. In a very recent study using a duplex PCR assay without DNA sequencing (Bigarre et al. 2009), it was shown that the J and U/I lineages are present in Europe. In order to estimate the influence of viral genetics on pathology and mortality, further experimental infections with different genetically characterized KHV isolates would be necessary.

To our knowledge, this is the first study based on a PCR method and nucleotide sequencing that used a larger number of samples and allowed all 3 strains of $\mathrm{KHV}$ to be distinguished. However, it is important to note the possibility that this method may not be able to differentiate the American from the Israeli strain, since the 2 bp deletion in the ORF40 region of the American strain could have happened in vitro (Aoki et al. 2007). Further investigations of KHV isolates from all over the world are necessary to confirm and complete the subgrouping of KHV. For the correct depiction of the evolutionary and geographical relationship of KHV isolates, other genes and whole genomes of additional isolates should be analyzed. The evolution and further epidemiological analysis of KHV isolates may also be important for any future vaccine developments against KHV.

Acknowledgements. We thank Dr. K. Way of the Cefas Weymouth Laboratory (UK) for supplying the UK isolate. This study was financed by the Austrian Federal Ministry of Health, Family and Youth.

Editorial responsibility: Gregory Chinchar, Jackson, Mississippi, USA

\section{LITERATURE CITED}

Aoki T, Hirono I, Kurokawa K, Fukuda H and others (2007) Genome sequences of three koi herpesvirus isolates representing the expanding distribution of an emerging disease threatening koi and common carp worldwide. J Virol 81:5058-5065

Bercovier H, Fishman Y, Nahary R, Sinai S and others (2005) Cloning of the koi herpesvirus (KHV) gene encoding thymidine kinase and its use for a highly sensitive PCR based diagnosis. BMC Microbiol 5:13

- Bigarre L, Baud M, Cabon J, Antychowicz J and others (2009) Differentiation between cyprinid herpesvirus type-3 lineages using duplex PCR. J Virol Methods 158:51-57

Davison AJ, Eberle R, Ehlers B, Hayward GS and others (2009) The order Herpesvirales. Arch Virol 154:171-177

Gilad O, Yun S, Andree KB, Adkison MA and others (2002) Initial characteristics of koi herpesvirus and development of a polymerase chain reaction assay to detect the virus in koi, Cyprinus carpio koi. Dis Aquat Org 48:101-108

Gilad O, Yun S, Adkison MA, Way K and others (2003) Molecular comparison of isolates of an emerging fish pathogen, koi herpesvirus, and the effect of water temperature on mortality of experimentally infected koi. J Gen Virol 84: 2661-2667

Haenen O, Way K, Bergmann S, Ariel E (2004) The emergence of KHV and its significance to European aquaculture. Bull Eur Assoc Fish Pathol 24:293-307

Ishioka T, Yoshizumi M, Izumi S, Suzuki K and others (2005) Detection and sequence analysis of DNA polymerase and major envelope protein genes in koi herpesviruses derived from Cyprinus carpio in Gunma prefecture, Japan. Vet Microbiol 110:27-33

Kurita J, Yuasa K, Ito T, Sano M and others (2009) Molecular epidemiology of koi herpesvirus. Fish Pathol 44:59-66

> Rosenkranz D, Klupp BG, Teifke JP, Granzow H and others (2008) Identification of envelope protein pORF81 of koi herpesvirus. J Gen Virol 89:896-900

Submitted: July 20, 2009; Accepted: October 22, 2009 Proofs received from author(s): January 21, 2010 